\title{
Protocol for a Qualitative Study on Doctors' Opinions on and Experiences of Exceptionally Good Doctors
}

\author{
Christoph Schnelle (D), Mark A Jones (D)
}

Institute of Evidence-Based Healthcare, Bond University, Robina, QLD, 4226, Australia

Correspondence: Christoph Schnelle, Institute of Evidence-Based Healthcare, Bond University, 14 University Drive, Robina, QLD, 4226, Australia, Email christoph.schnelle@student.bond.edu.au

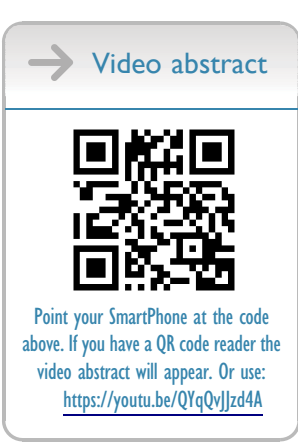

Objective: Doctors have a varying effect on patients' physical health. This means that there are doctors that are more effective than others. Even though the doctor is a part of very many medical interactions, it is not known in which way exceptionally good doctors differ from their peers. After authoring two systematic and one methodological review on identifying exceptional doctors, the authors in this qualitative interview-based study take a bottom-up, inductive approach to answer the question of what makes an exceptionally good doctor.

Methods: About 10-15 semi-structured interviews of medical doctors of any specialty who speak English will be conducted. Recruitment will be through the authors' network and their referrals. Questions will be whether they have an opinion on what makes an exceptionally good doctor, whether they have met such a person and how did this doctor differ from other doctors. The interviews will be done by a 62 -year old $\mathrm{PhD}$ student who is not a clinician but has extensive experience in having personal conversations as a financial adviser. This could be helpful as the interviewer is only aware that there are exceptionally good doctors but has no notion how exceptionally good doctors differ from their colleagues.

Analysis: A six-phase thematic analysis in an experiential framework as per Braun and Clarke will be implemented with the aim to find out what the doctors think and have experienced. This is an inductive approach using a realist epistemological position under the assumption that it is possible to acquire truthful knowledge on what makes exceptionally good doctors.

Discussion: Previous qualitative research on exceptionally good doctors consisted of interviewing author-selected exceptionally good doctors. This study takes a step back from this approach by asking the peers of exceptionally good doctors how they define being exceptionally good and how they experience such doctors.

Keywords: qualitative study, thematic analysis, doctors' performance

\section{Plain Language Summary}

There is evidence that some doctors are exceptionally good, even if at least in terms of patients' physical health outcomes, however, there is little research on how such exceptionally good doctors differ from their peers. There is research showing that good doctors deal well with people, are competent, and ethical but almost none on doctors who are exceptionally good. This paper outlines how the authors will try to find out more about what doctors think it takes to make an exceptional doctor and learn more about doctors' experiences with exceptionally good doctors, through a series of interview. The understanding gained from these interviews may then be used in future to improve medical doctors' abilities and performance. 


\section{Strengths and Limitations of This Study}

- One strength of this work is the relevant experience of the authors in recently systematically reviewing over 10,000 studies on doctors' or surgeons' effect on patients' physical health.

- Another strength is that the interviewer is not a clinician and therefore the doctors will not feel the need to take account of the opinion of a colleague during the interview.

- A further strength is that there are no pre-conceived notions on what makes an exceptionally good doctor beyond the opinion that there are such doctors, allowing for a wide range of possible outcomes of this research study.

- A limitation is that this is a qualitative study with a limited number of interviewees on a wide subject, and therefore may not achieve saturation, ie it is possible that many more interviews than the considered 10-15 may be needed.

- A second limitation is that, as all of the subjects will be English-speaking doctors and most of them are expected to be residing in Australia, with perhaps some from North America and Europe, it is uncertain whether the findings could be generalised to other regions, particularly developing nations.

- Finally, due to the heterogeneity regarding medical/surgical specialties, types of interventions, and types of outcomes relevant to different interventions, there may be differing criteria on what makes an exceptionally good doctor for different medical/surgical specialties.

\section{Background}

In a classic ${ }^{1}$ paper from 1955, Michael Balint ${ }^{2}$ raised the possibility that "the most frequently used drug in general practice was the doctor himself" and over the next seven pages he details how a doctor should "prescribe himself". At the time of writing, this paper has 86 citations as per Scopus ${ }^{3}$ and over 4800 citations in google scholar, a discrepancy which points to an impact that is largely outside the traditional scientific literature. On a similar theme, a special issue of The British Medical Journal (BMJ) in 2002 attempted to answer the question, "What's a good doctor and how do you make one?". In one article, letters from individual doctors and others who tried to answer this question were published. Among which, one quote was: "There is not a single piece of evidence or the means to measure whether a doctor is good or bad". 5

Previous research has shown that there can be exceptionally poor performing doctors, ${ }^{6,7}$ to the point of legal consequences $^{6}$ and historical precedents of malpractice. ${ }^{6,7}$ Systematic reviews have evaluated the influence of surgical experience measured in case volume or years of practice, recognizing it as a key factor of medical performance and acknowledging a learning curve. ${ }^{8,9}$ Recent evidence also suggests that the provider expectations can substantially affect patient outcomes. ${ }^{10}$ While research on doctors' effect in many non-surgical specialties is rare, there is evidence in primary care, ${ }^{11}$ obstetrics ${ }^{12}$ and acute care ${ }^{13}$ that physician factors had a sizeable effect on health outcomes. Furthermore, there are publications where author-selected outstanding practitioners are investigated. ${ }^{14-16}$ "Outstanding" is defined as the mastery of identified skills that would improve patient care and reaffirm medicine's calling, ${ }^{14,16}$ and recognized practice of patient-centred care. $^{15}$

The authors of this proposal have recently completed two systematic reviews on existing research of the doctors' effect on patients' physical health. Both studies have revealed that there is an unknown doctors' effect even after controlling for the intervention and all known information such as patient risk factors, hospital and doctor demographics, and experience. It has further been established that there are positive outliers among doctors, ie doctors whose patients' physical health outcomes are substantially above average. Hence, detecting a significant doctors' effect also implies that there are doctors who perform better than others. Knowing what identifies exceptional doctors could make it possible for other doctors to learn the same characteristics or practices, ${ }^{14}$ and thereby improving patients' physical health outcomes. If such skills can be passed on to other doctors, then this could be an effective way to improve healthcare.

The current level of knowledge on attributes of good, not necessarily exceptionally good, doctors is also limited, as Abu-Hilal et al's study illustrates. ${ }^{17}$ The authors constructed a "standard questionnaire" to identify attributes considered important in being a good doctor. The attributes identified included clinical ability, to be approachable, appreciate limitations, and knowledge. However, this type of study does not allow a deeper understanding of the phenomenon. A similar but more rigorous qualitative study by Churchill \& Schenck identified eight pivotal skills of exceptionally good 
doctors regarding patient-relationship ${ }^{14}$ "do the little things; take time; be open and listen; find something to like; remove barriers; let the patient explain; share authority; and be committed".

Furthermore, on good doctors, Steiner-Hofbauer et $\mathrm{al}^{18}$ have systematically reviewed the existing literature regarding the topic of "good doctors" in different stakeholder groups, and they have found 6 studies on doctors of different specialities, ${ }^{19-23}$ plus studies gathering the opinions of medical students, patients, the general population, nurses, and children. Steiner-Hofbauer et $\mathrm{al}^{18}$ have stated that what makes a good doctor is not clearly defined yet, and that the answer to such a question will definitely vary depending on the type of population you ask. ${ }^{24}$

Others have provided opinion pieces, ${ }^{25-35}$ an analysis of publications on stakeholders' opinions on character strengths of a good doctor, ${ }^{36}$ patient and physician perspectives, ${ }^{37}$ and a thesis on the changing perceptions from 1910-2010 on the good doctor in education. ${ }^{38}$

Currently it is still not known what makes an exceptionally good doctor. This research project aims to address this knowledge gap by conducting a study to identify and describe exceptional doctors. As there is little literature on this subject, an exploratory qualitative study is needed. This approach is commonly used to generate theory when previous knowledge is limited. The selected approach consists of semi-structured interviews and Braun and Clarke's thematic analysis. $^{39-41}$

\section{Materials and Methods Study Design}

The qualitative approach for this study involves semi-structured interviews of medical doctors of any specialty who are available for interviewing. The only other inclusion criterion is that they speak English. Recruitment will be achieved through acquaintances, contacting authors of relevant research papers, contacting medical practices or medical doctors with an internet contact, the GP recruitment program of the Institute of Evidence-based Healthcare of Bond University, and any doctors referred by any of these groups.

\section{Semi-Structured Interviews}

Participants will be interviewed in person or via zoom or via telephone or any other similar way at a time and place of their convenience. It will be emphasised that participants are free to terminate the interview at any time or not to answer any question.

The potential participants will indicate their consent by clicking a link that takes them to an online survey consisting solely of the participant information sheet and the consent form, and they can confirm their consent by clicking on a "I agree to participate in this research project" or "I do not agree". Each potential participant will be given an individual link so the survey can greet them by name and record their consent.

The interviews are expected to take between 15 minutes to an hour, depending on the amount a participant wishes to contribute. There may be a subsequent, shorter interview to clarify matters.

The interview guide will include three open-ended questions, as follows:

a. What, in your opinion and experience, makes an exceptional doctor?

b. Have you ever met an exceptional doctor?

c. If yes, how did this doctor differ from other doctors?

There is scope for participants to raise issues not anticipated. The interviews will be, as recommended in qualitative research, flexible and responsive to the participant. Interviews will continue either until 10-15 interviews have been done or until saturation has been achieved, ie when additional participants only add marginal new relevant data; whichever is earlier.

The interviews will be recorded in audio or video format. Where available, video via zoom, skype or Microsoft Teams (Teams) will be used, otherwise audio-only zoom, skype or Teams, or, if the interviews are done in person or by telephone, an audio recorder will be employed.

The interviewees will receive a transcript of the interview and will be able to edit their answers. This will occur after the interviews have been transcribed. The transcripts will be sent to the interviewees by email, or mail if email is not 
available, and they will be offered to edit their answers before further processing by the researchers. If they choose to edit their answers they will be followed-up until they have done so, and they are free to change their decision to not wishing to edit, or to indicate their withdrawal from the study.

\section{The Interviewer (Reflexivity)}

The lead researcher will be doing all the interviews. He is a 62 -year-old $\mathrm{PhD}$ student whose profession is being a financial adviser. He has experience in running focus groups to design a lengthy health survey for a group of women. In his professional work, he has extensive experience talking to a varied group of people with very different backgrounds about their financial matters. Many of these conversations become very personal without being intrusive, and without imposing his own opinions as that would impair the client's ability to outline their situation and their own, at times unexpected, ways to respond to their situation.

This background will be useful for several reasons. One is that describing an experience with an exceptionally good doctor can be relaying a very personal event. Another is that any displayed bias can reduce the effectiveness of the interview.

It could be an advantage that the lead researcher is not a medical or health care practitioner as he will have fewer or no pre-conceived notions on exceptional doctors and the doctors will not feel the need to modify their opinions in the presence of a fellow professional. It could be a source of bias that, due to the two systematic reviews, the lead researcher is aware that there are doctors who have exceptionally positive effect on the physical health of the patients that they treat. However, the results of those previous systematic reviews show that there are exceptionally good doctors but do not suggested a reason for outperformance, so the only prior assumption is the lack of knowledge regarding what makes a good doctor.

\section{Analysis}

This is a qualitative study using Thematic Analysis as practised by Braun and Clarke. ${ }^{39-41}$ As per Norris et al, ${ }^{42}$ Thematic Analysis

is a highly flexible methodology that can result in rich, complex accounts from different research participants, underlying similarities and differences, as well as generating unanticipated insights.

Thematic analysis will be used in an experiential framework, ie seeking to understand what doctors think and experienced in regards to exceptional doctors. The approach will be inductive while using a realist epistemological (what is the nature of knowledge) position which assumes that it is possible to obtain truthful knowledge on what makes exceptional doctors. As Braun and Clarke ${ }^{43}$ state

Inductive analysis is therefore a process of coding the data without trying to fit it into a preexisting coding frame, or the researcher's analytic preconceptions.

Phase one is transcribing and familiarisation with the transcripts.

Phase two is systematic coding of the data using codes that are relevant to the research question.

Phase three is development of candidate themes by examining the codes for similarities and overlap, similar to principal component analysis in survey responses.

Phase four is reviewing the candidate themes against the coded data for fit, and whether the themes tell a coherent story about the transcripts.

Phase five is going backward and forward between phases three and four, until the themes have been finalised.

Phase six is writing up, assembling and editing the resulting themes, including short data extracts to support any analytical claims.

\section{Patient and Public Involvement}

There is no patient or public involvement at this stage, though a survey for the public may be constructed after this project. 
The results will be disseminated through scientific journals as well as magazines or websites aimed at medical doctors and the wider public.

\section{Ethical Considerations}

We will use consent forms for all interview participants. Names will be erased from the interviews or any other delivery document and, in the summary of the findings, contact details will be erased as well. All documents will be kept in secured premises of the lead researcher. Contact details will be destroyed after the summary reports have been sent.

One version of the transcripts will have identifying data but will not be processed further. A version of the transcript without identifying data will be used for further analysis. Video data is by definition identifiable but will only be available outside the research team if there is explicit informed consent from all participants in any interview.

The NVivo software is a secure qualitative data analysis tool used by the lead researcher on his password-protected computer.

\section{Discussion}

There is very little research on whether there are exceptionally good doctors, and, if they exist, the data is limited regarding who they are and how they differ from their peers. Previous qualitative research in this area was either on author-selected outstanding practitioners, ${ }^{14-16}$ or about what patients think a good doctor is. ${ }^{44-46}$ What this research adds is details on what doctors themselves consider to be criteria for exceptionally good doctors, and what they have experienced about them. Future research could then extend this approach comparing the definitions and experiences obtained from such doctors to the patients' point of view.

Who is a good doctor? And what it takes to make an exceptionally good practitioner? Such questions are crucial to anyone involved in the healthcare practice, and more importantly for medical education. However, yet, responses to these questions are still elusive and not easy to answer, since there is no clear definition about the essence of a good doctor, and the answers most certainly vary depending on whom you ask according to their different needs and interests. ${ }^{47}$ Prior studies seeking the answer of who a good doctor is have involved students, doctors, patients, and nurses. The aspects covered have included the general interpersonal qualities, communication skills and patient involvement, medical experience and skills, the doctor-patient relationship ethics, management and leadership qualities, teaching and supervision skills, research, and continuous education. ${ }^{18}$ Interestingly, it was found that patients have tended to evaluate the doctor according to their communication skills, while doctors were more focusing on medical skills. Herein, we intend to retrieve more answers about the essence of an exceptionally good doctor and the qualities behind their outperformance via semi-structured interviews of broader samples of medical doctors of any specialty.

In the future, the results of this project could be compared with the opinions and experiences of doctors who have been objectively identified as being exceptionally good in large cohort studies and those doctors and other practitioners who have worked with such doctors. This could provide useful information about how much the opinions of doctors are shared by their exceptionally good peers.

\section{Disclaimer}

The views expressed are those of the authors and not necessarily those of Bond University.

\section{Data Storage}

Data will be stored in a secured location at Bond University for a period of 5 years after the end of this project as per 601.3/C150 of the Qld Government University Sector Retention and Disposal Schedule in accordance with the guidelines set out by the Bond University Human Research Ethics Committee.

\section{Provenance and Peer Review}

Not commissioned; peer reviewed for ethical and funding approval prior to submission. 


\section{Patient and Public Involvement}

No patients, carers, or members of the public were formally involved in setting the research plan, defining research questions, or outcome measures.

\section{Ethics Approval}

Ethical approval Number CS03393 has been received from the Bond University Human Research Ethics Committee on September 27th, 2021.

\section{Consent}

The participants will only be interviewed after they have provided their consent.

\section{Author Contributions}

All authors contributed to conception and design, acquisition of data, interpretation of data, and drafting the article or revising it critically; CS provided the initial research idea and drafted the protocol as part of his PhD studies at Bond University. MJ was his principal supervisor who assisted and guided throughout all areas, and substantially revised the article. All authors have agreed on the journal to which the article was submitted, gave final approval of the version to be published, and agree to be accountable for all aspects of the work.

\section{Funding}

This review has been funded by the first author as part of his $\mathrm{PhD}$ studies or by the $\mathrm{PhD}$ study budget provided by Bond University to the first author. No external funding was received.

\section{Disclosure}

All authors declare no support from any organisation for the submitted work; no financial relationships with any organisations that might have an interest in the submitted work in the previous three years; no other relationships or activities that could appear to have influenced the submitted work.

\section{References}

1. Curran J. The doctor, his patient and the illness. BMJ. 2007;335(7626):941. doi:10.1136/bmj.39384.467928.94

2. Balint M. The doctor, his patient, and the illness. Lancet. 1955;265(6866):683-688. doi:10.1016/S0140-6736(55)91061-8

3. Elsevier. Scopus. Elsevier; 2021.

4. Hurwitz B. What's a good doctor, and how can you make one? BMJ. 2002;325(7366):667-668. doi:10.1136/bmj.325.7366.667

5. Rizo CA, Jadad AR, Enkin M. What's a good doctor and how do you make one?: Doctors should be good companions for people. BMJ. 2002;325 (7366):711. doi:10.1136/bmj.325.7366.711

6. Dyer C. Investigators should be trained to "think dirty" about cause of death, Shipman report says. BMJ. 2003;327(7407):123. doi:10.1136/ bmj.327.7407.123-c

7. Seidelman WE. The professional origins of Dr. Joseph Mengele. Can Med Assoc J. 1985;133(11):1169-1171.

8. Wilt TJ, Shamliyan TA, Taylor BC, et al. Association between hospital and surgeon radical prostatectomy volume and patient outcomes: a systematic review. J Urol. 2008;180(3):711. doi:10.1136/bmj.325.7366.711

9. Maruthappu M, Gilbert BJ, El-Harasis MA, et al. The influence of volume and experience on individual surgical performance: a systematic review. Ann Surg. 2015;261(4):642-647. doi:10.1097/SLA.0000000000000852

10. Chen P-HA, Cheong JH, Jolly E, et al. Socially transmitted placebo effects. Nat Hum Behav. 2019;3(12):1295-1305. doi:10.1038/s41562-0190749-5

11. Moreau A, Boussageon R, Girier P, et al. The "doctor" effect in primary care. Presse Med. 2006;35(6I):967-973. doi:10.1016/S0755-4982(06) 74729-7

12. Harley M, Mohammed MA, Hussain S, et al. Was Rodney Ledward a statistical outlier? Retrospective analysis using routine hospital data to identify gynaecologists' performance. Br Med J. 2005;330(7497):929-932. doi:10.1136/bmj.38377.675440.8F

13. Beckett DJ, Spears M, Thomson E. Reliable consultant level data from an acute medical unit: a powerful tool for improvement. $J R$ Coll Physicians Edinb. 2018;48(2):108-113. doi:10.4997/jrcpe.2018.202

14. Churchill LR, Schenck D. Healing skills for medical practice. Ann Intern Med. 2008;149(10):720-724. doi:10.7326/0003-4819-149-10-2008111800000619017590

15. Hanyok LA, Hellmann DB, Rand C, et al. Practicing patient-centered care: the questions clinically excellent physicians use to get to know their patients as individuals. Patient. 2012;5(3):141-145. doi:10.2165/11599530

16. Schenck D, Churchill L. Healers: extraordinary clinicians at work. Oxford University Press; 2011. 
17. Abu-Hilal M, Morgan EC, Lewis G, et al. What makes a good doctor in the 21st century? A qualitative study. Br J Hosp Med. 2006;67(7):375-377. doi:10.12968/hmed.2006.67.7.21623

18. Steiner-Hofbauer V, Schrank B, Holzinger A. What is a good doctor? Wien Med Wochenschr. 2018;168(15-16):398-405. doi:10.1007/s10354-0170597-8

19. Herzig S, Biehl L, Stelberg H, et al. What makes a doctor a good doctor? A content analysis of assessments by a sample of doctors. Dtsch Med Wochenschr. 2006;131(51-52):2883-2888. doi:10.1055/s-2006-957216

20. Kim JH, Tor PC, King J, et al. A Korean survey on qualities and definition of a good psychiatrist. J Korean Med Sci. 2015;30(5):632-638. doi:10.3346/jkms.2015.30.5.632

21. Kliems H, Witt CM. The good doctor: a qualitative study of German homeopathic physicians. J Altern Complement Med. 2011;17(3):265-270. doi:10.1089/acm.2010.0158

22. Lambe P, Bristow D. What are the most important non-academic attributes of good doctors a Delphi survey of clinicians. Med Teach. 2010;32(8): e347-e54. doi:10.3109/0142159X.2010.490603

23. Miratashi Yazdi SN, Nedjat S, Majdzadeh R, et al. Who is a good doctor? Patients \& physicians' perspectives. Iran J Public Health. 2015;44 (1):150-152.

24. Bardgett RJM, Darling JC, Webster E, et al. What makes a good children's doctor? Exploring the child perspective in the OSCE setting. Med Teach. 2016;38(5):471-475. doi:10.3109/0142159X.2015.1060301

25. Conti CR. What makes a good doctor? Clin Cardiol. 2005;28(11):496-498. doi:10.1002/clc.4960281102

26. Bates C. The good doctor. Clin Med. 2001;1(2):128-131. doi:10.7861/clinmedicine.1-2-128

27. Smith DH. How to be a good doctor in the 1990s: stand and deliver. Am J Obstet Gynecol. 1994;170(6):1724-1728. doi:10.1016/S0002-9378(94) 70347-7

28. Magauran CE, Brennan M. Being a “Good Doctor”. J Palliat Med. 2008;11(3):506-508. doi:10.1089/jpm.2007.0206

29. Davis K, Carbone R, Fredericks J, et al. What makes a good doctor: a qualitative study of patient perspectives; 2021.

30. Simpson L. What makes a good surgeon? J Natl Med Assoc. 2008;100(2):261-264. doi:10.1016/S0027-9684(15)31216-5

31. Crile GW. The most important factor in the treatment of war wounds and the most important factor in civilian surgery-The Good Surgeon. Ann Surg. 1919;70(4):385-387. doi:10.1097/00000658-191910000-00001

32. Darzi A, Smith S, Taffinder N. Assessing operative skill: Needs to become more objective. BMJ. 1999;318(7188):887-888. doi:10.1136/ bmj.318.7188.887

33. Gandhi J. Making of a Surgeon. Al Ameen J Med Sci. 2019;12(2):54-55.

34. Arora S, Sevdalis N, Suliman I, et al. What makes a competent surgeon?: Experts' and trainees' perceptions of the roles of a surgeon. Am J Surg. 2009;198(5):726-732. doi:10.1016/j.amjsurg.2009.01.015

35. Jackson B. What makes an excellent surgeon? Obes Surg. 2019;29(4):1087-1089. doi:10.1007/s11695-019-03778-8

36. Jones D. What are the character strengths of a good doctor? Jubilee Centre Charact Virtuesies. 2013.

37. Miratashi Yazdi SN, Nedjat S, Arbabi M, et al. Who is a good doctor? Patients \& physicians' perspectives. Iran J Public Health. 2015;44(1):150152.

38. Whitehead CR. The good doctor in medical education 1910-2010: a critical discourse analysis: University of Toronto (Canada); 2011.

39. Braun V, Clarke V. What can "thematic analysis" offer health and wellbeing researchers? Int J Qual Stud Health Well-Being. 2014;9:26152. doi:10.3402/qhw.v9.26152

40. Braun V, Clarke V. Successful Qualitative Research: A Practical Guide for Beginners. Sage; 2013.

41. Clarke V, Braun V. Thematic analysis. In: Encyclopedia of Critical Psychology. New York: Springer; 2014:1947-1952.

42. Norris JM, White DE, Nowell L, et al. How do stakeholders from multiple hierarchical levels of a large provincial health system define engagement? A qualitative study. Implement Sci. 2017;12(1):98. doi:10.1186/s13012-017-0625-5

43. Braun V, Clarke V. Using thematic analysis in psychology. Qual Res Psychol. 2006;3(2):77-101. doi:10.1191/1478088706qp063oa

44. Klingenberg A, Bahrs O, Szecsenyi J. [How do patients evaluate general practice? German results from the European Project on Patient Evaluation of General Practice Care (EUROPEP)]. Z Arztl Fortbild Qualitatssich. 1999;93(6):437-445. German.

45. Mercer SW, McConnachie A, Maxwell M, et al. Relevance and practical use of the Consultation and Relational Empathy (CARE) measure in general practice. Fam Pract. 2005;22(3):328-334. doi:10.1093/fampra/cmh730

46. Schattner A, Rudin D, Jellin N. Good physicians from the perspective of their patients. BMC Health Serv Res. 2004;4(1):26. doi:10.1186/14726963-4-26

47. Hofhansl A, Horn W, Kainberger F, et al. To be a good doctor“: Wie werden Medizinstudierende auf die Zukunft vorbereitet? Wien Med Wochenschr. 2015;165(5):83-85. doi:10.1007/s10354-015-0349-6

Advances in Medical Education and Practice

Dovepress

\section{Publish your work in this journal}

Advances in Medical Education and Practice is an international, peer-reviewed, open access journal that aims to present and publish research on Medical Education covering medical, dental, nursing and allied health care professional education. The journal covers undergraduate education, postgraduate training and continuing medical education including emerging trends and innovative models linking education, research, and health care services. The manuscript management system is completely online and includes a very quick and fair peer-review system. Visit http://www.dovepress.com/testimonials.php to read real quotes from published authors.

Submit your manuscript here: http://www.dovepress.com/advances-in-medical-education-and-practice-journal 